\title{
Stretchable Biofuel Cells with Silver NanoWiring on a Polydimethylsiloxane Substrate
}

\author{
Yusuke Fujimagari, Yudai Fukushi, and Yasushiro Nishioka* \\ Department of Precision Machinery, College of Science and Technology, Nihon University, \\ 7-24-1 Narashinodai, Funabashi, Chiba 274-8501, Japan \\ E-mail: nishioka@eme.cst.nihon-u.ac.jp
}

\begin{abstract}
In this study, we fabricated a flexible, stretchable glucose-biofuel cell with silver nanowires (AgNWs) on a dimethylpolysiloxane substrate. The biofuel cell investigated consists of a porous carbon anode (area of $30 \mathrm{~mm}^{2}$ ) modified by glucose oxidase and ferrocene, and a cathode (area of $30 \mathrm{~mm}^{2}$ ) modified by bilirubin oxidase. The anode and the cathode were connected with AgNWs. The maximum power of $0.29 \mu \mathrm{W}$ at $180 \mathrm{mV}$, which corresponds to a power density of $0.98 \mu \mathrm{W} / \mathrm{cm}^{2}$, is realized by immersing the biofuel cell in a phosphate buffer solution with a glucose concentration of $100 \mathrm{mM}$, at room temperature.
\end{abstract}

Keyword: Glucose biofuel cell, silver nanowires, stretchable and flexible wiring

\section{Introduction}

Recently, enzymatic biofuel cells that use glucose in a human body to produce electricity have been of special interest. This is because they work under mild conditions (room temperature, neutral $\mathrm{pH}$ and atmospheric pressure), which make them amenable to use in the human body [1-12]. However, when these devices are used in the human body, the flexibility and stretchability of biofuel cells are among their most important features. Recently, as a potential candidate for a flexible biofuel cell to be used in vivo, Fukushi et al. reported a flexible glucose fuel cell on a polyimide (PI) sheet because PI offers good biocompatibility, with high thermal stability and flexibility [13]. In addition, Miyake et al. fabricated flexible biofuel cells with a structure of sandwiched d-fructose dehydrogenase in carbon fabric (CF) $[14,15]$. Although these devices were flexible, they were not stretchable. The fabrication of stretchable electrodes and wiring is as necessary as bending flexibility to realize wearable biofuel cells.

In contrast, silver nanowires (AgNWs) have drawn much attention because they are both electrically conductive and stretchable [16-25]. Polydimethylsiloxane (PDMS) is a material that has been extensively investigated for use in many biodevices because it is biocompatible, flexible, and stretchable [26-29]. For example, $\mathrm{Xu}$ et al. reported stretchable light emitting diodes with strain sensors, with AgNWs embedded in a PDMS substrate. The AgNWs were fabricated by pouring a PDMS solution on AgNW patterns on a substrate, followed by peeling off the PDMS layer from the substrate. The resistance of the AgNWs increased only slightly, even after being stretched up to $80 \%$ of their original length [30]. However, there has been no report on creation of a stretchable glucose biofuel cell using AgNWs. In this study, we fabricated a glucose biofuel cell with flexible, stretchable silver nanowiring on a PDMS substrate.

\section{Methods}

\subsection{Power Generation Mechanism}

The biofuel cell investigated in this research consists of a porous carbon anode modified by glucose oxidase (GOD) and ferrocene, and a cathode modified by bilirubin oxidase (BOD). Figure 1 shows the power generation principle. Electrons removed by GOD are transferred to the anode through the ferrocene mediator, and protons are released from glucose at the same time. The electron flow though the resistance, and are 
delivered to the cathode where oxygen is reduced by these electrons and protons. The generated power can be diverted through an external circuit connected between the anode and the cathode.

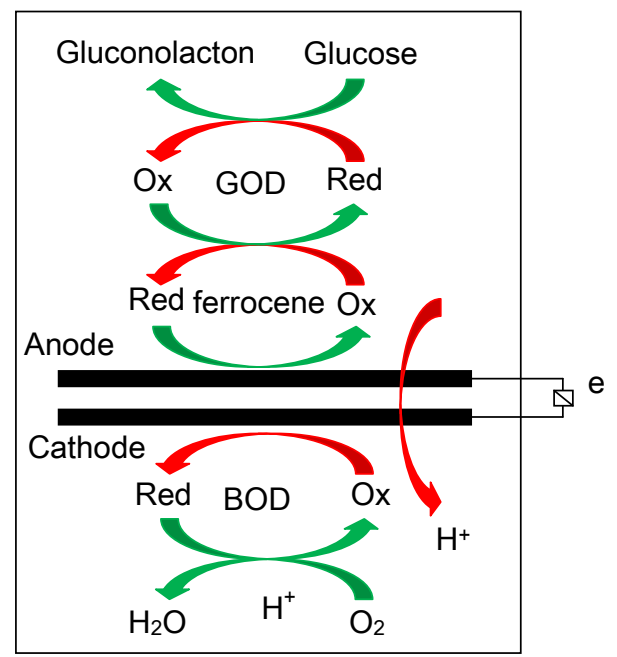

Fig. 1. Possible mechanism of power generation.

\subsection{Design of wiring and electrodes}

Figure 2 shows the layout of the cathode and anode. Both the anode and cathode had a width of $3 \mathrm{~mm}$ and a length of $10 \mathrm{~mm}$. The gap between the anode and cathode was $1 \mathrm{~mm}$. The anode and cathode were deposited on AgNWs with a width of $3 \mathrm{~mm}$ and length of $25 \mathrm{~mm}$.
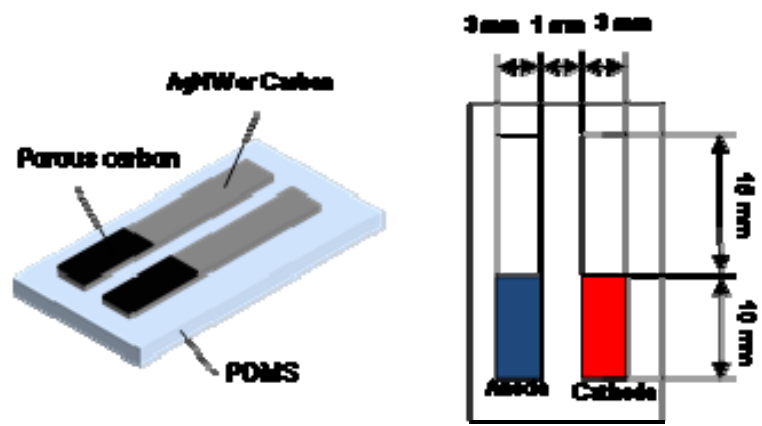

Fig. 2. Design of stretchable wiring and electrodes.

\subsection{Fabrication of mold for AgNWs}

The process for fabricating the electrode molds is shown in Fig. 3. First, a photoresist (PR, S1818 positive) was spin-coated onto a silicon substrate (Fig. 3a). Next, the electrode mold structure was optically defined using photolithography (Fig. 3b). Then, the silicon substrate was etched anisotropically (Bosch process), in an inductively coupled plasma (ICP) etcher (MUC21, Sumitomo Precision Products Co. Ltd.) with etching depth of $100 \mu \mathrm{m}$ (Fig. 3c). Once the photoresist was removed, the Si mold was considered fabricated.

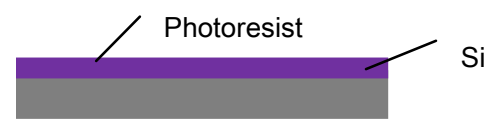

(a)

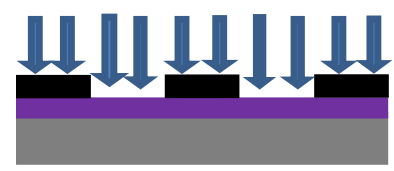

(b)

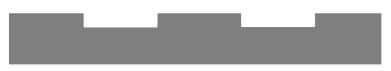

(c)

Fig. 3. Fabrication processes for the $\mathrm{Si}$ mold: (a) Photoresist spin-coating, (b) Exposure, (c) Si ICP etching.

\subsection{Electrode fabrication procedure}

Figure 4 shows the processes for fabricating the wiring. First, the mold was cleaned in acetone, and ethanol, for $15 \mathrm{~min}$ each, followed by drying at $120{ }^{\circ} \mathrm{C}$ in air (Fig. 4a). Ten microliters of an ethanolic solution of AgNW (Silver Nanowires C, Novarials Corporation) was dropped onto the electrode patterns of the mold (Fig. 4b). The structure was dried at $80{ }^{\circ} \mathrm{C}$ for $20 \mathrm{~min}$. Since the depth of the wiring patterns was $100 \mu \mathrm{m}$, the thickness of the AgNW layers was considered to be around $100 \mu \mathrm{m}$. A PDMS solution (DOW CORNING TORAY SILPOT $184 \mathrm{~W} / \mathrm{C}$, Dow Corning Toray Co., Ltd) and a hardening agent were mixed at a weight ratio of 10:1. The PDMS solution was dropped onto the mold, which was dried in vacuum for $20 \mathrm{~min}$ to release air bubbles from the PDMS (Fig. 4c). The PDMS layer with AgNW wirings was then baked in a vacuum furnace at $80{ }^{\circ} \mathrm{C}$ for $30 \mathrm{~min}$ (Fig. 4d). As a reference, we also fabricated stretchable carbon wiring on the PDMS substrate by screen printing, using a mixed solution of PDMS with hardening agent, and Ketjenblack EC 300J (KB, Lion Inc.) at the ratio of 10:1. The estimated thickness of the carbon wiring was approximately $100 \mu \mathrm{m}$. Pt wiring was also sputter-deposited on the PDMS substrate, and the Pt layer had a thickness of 100 nm.

2.5 Fabrication of the carbon-modified electrodes

The surfaces of the carbon paste film were coated by screen-printing with Ketjenblack and 
polyvinylidene fluoride (PVDF, KUREHA, Inc.) mixed ink, which was then cured at $80^{\circ} \mathrm{C}$ for $1 \mathrm{~h}$.

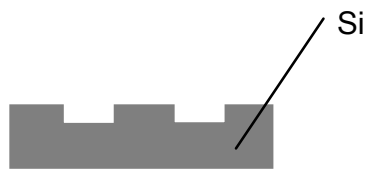

(a)

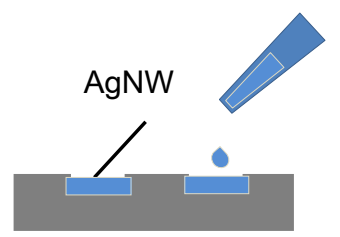

(b)

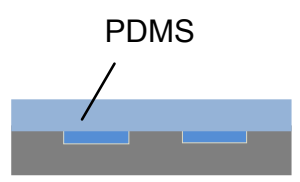

(c)

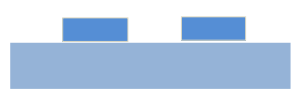

(d)
Fig. 4. Fabrication processes for $\mathrm{Ag}$ nanowiring on PDMS: (a) Cleaning, (b) Deposition of AgNW or carbon, (c) PDMS deposition, (d) Release from mold.

Figure 5 shows a photograph of a fabricated stretchable and flexible AgNW electrode on PDMS substrate.

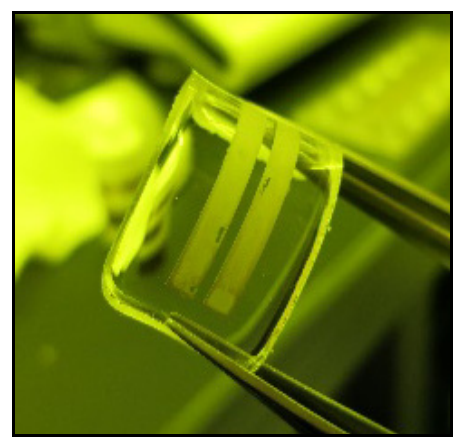

Fig. 5. Photograph of the fabricated stretchable and flexible Ag nanowiring on the PDMS substrate.

\subsection{Fabrication of the enzyme-modified electrodes}

A small amount of GOD $(0.05 \mathrm{mg})$ was mixed with $30 \mu 1$ of phosphate buffer solution (PBS, 50 $\mathrm{mM}, \mathrm{pH}$ 7.0). Then, $0.05 \mathrm{mg}$ of the ferrocene mediator was mixed with $30 \mu \mathrm{l}$ of PBS. Finally, 10 $\mu l$ of the resulting solutions was dropped onto the anode (surface area $30 \mathrm{~mm}^{2}$ ), and left to dry for 90 min. Similarly, $0.05 \mathrm{mg}$ of BOD was mixed with $30 \mu \mathrm{l}$ of PBS. Then, $10 \mu \mathrm{l}$ of the resulting solution was dropped onto the cathode (surface area 30 $\mathrm{mm}^{2}$ ) and left to dry for $90 \mathrm{~min}$. As a reference, carbon electrodes were also fabricated using similar conditions to those previously reported.

\subsection{Measurements}

Figure 6 shows a photograph of the biofuel-cell characterization system. Changes in resistance of the $\mathrm{Ag}$ or carbon wiring were measured by stretching the wiring. Each wire was stretched in 2-mm intervals using a device until it broke. Electrochemical measurements were performed in an air-saturated, $100 \mathrm{mM}$ phosphate buffer solution (PBS) of glucose, at room temperature. The power $W$ generated was evaluated by measuring the cell voltage while varying the external load resistance between 0 and $2.7 \mathrm{M} \Omega$ using a source meter (Keithley 2400 Source Meter). The following equation was used to calculate $W$ :

$$
W=V^{2} / R
$$

where $R$ is the load resistance, and $V$ is the generated voltage measured between the terminals of the biofuel cell. The power density was calculated by dividing $W$ by the area of the anode or cathode, which was $30 \mathrm{~mm}^{2}$.

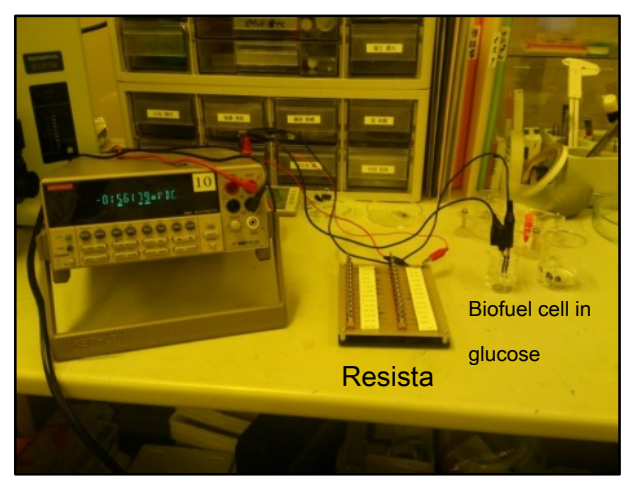

Fig. 6. Photograph of the system used to characterize the biofuel cell.

\section{Results and Discussion}

Figure 7 shows the change in the resistance of the Ag wiring on the PDMS substrates, as a function of the inverse of curvature. The resistance of $\mathrm{Pt}$ wiring sputtered onto the PDMS substrate (100 nm thick) is also shown for comparison. The resistance of the AgNWs showed only a very slight increase as the radius of curvature decreased. In contrast, the resistance of the $\mathrm{Pt}$ wiring increased noticeably as the radius of curvature became smaller, and was infinite at $7.5 \mathrm{~mm}$ radius of curvature because the $\mathrm{Pt}$ film fractured due to its stiffness. 


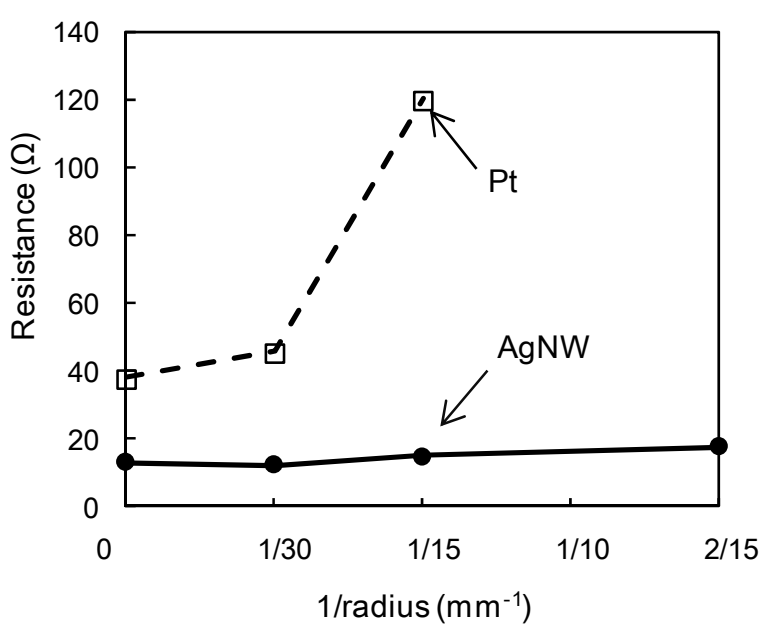

Fig. 7. The resistance of the Pt and AgNW electrodes versus inverse of the radius of the curvature.

Figure 8 shows the resistance of the AgNW and carbon electrodes as a function of elongation. The resistance of the AgNW electrode increased from 11.5 to $175.6 \Omega$ as the elongation increased from $0-100 \%$, while the resistance of the carbon electrode increased from 20.9 to $939 \mathrm{k} \Omega$. The carbon electrode fractured when elongation exceeded $120 \%$, while the AgNW electrode was more stable, with smaller change in resistance.

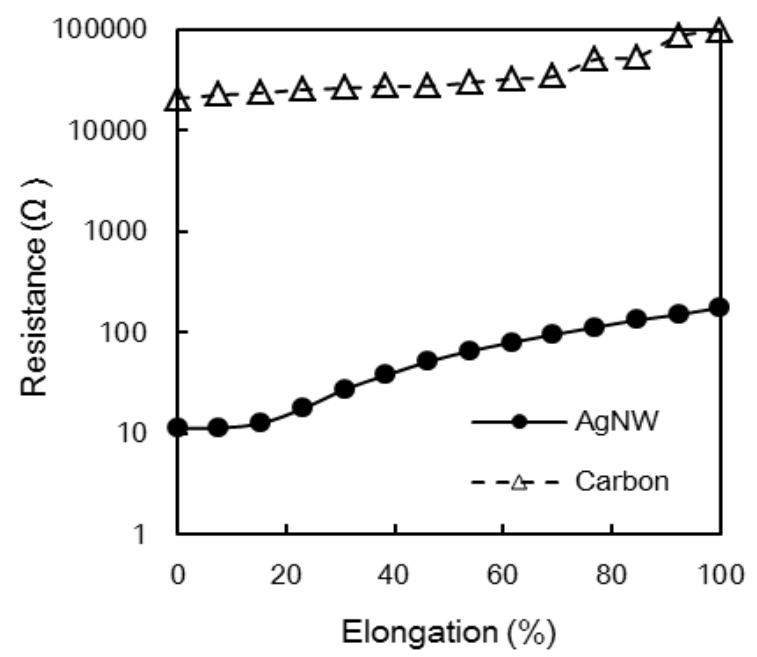

Fig. 8. Change in resistance of the $\mathrm{AgNW}$ and carbon electrodes as a function of elongation.

The Pt resistance at the radius of curvature of $7.5 \mathrm{~mm}$ became infinite, indicating a fracture of the Pt film. Lacour et al. reported that metal films such as $\mathrm{Pt}$ showed surface cracking after elongation exceeding 20\% [31]. In contrast, the Ag nanowiring showed little change in its resistance, suggesting that it was very flexible. The carbon wiring also proved flexible; however, the resistance of the carbon wiring was more than 1000 times greater than that of the Ag nanowiring (Fig. 8). Thus, it was concluded that AgNWs were the most suitable material for flexible wiring in flexible biofuel cells.

Figure 9 shows the relationships between the power density and the voltage for the biofuel cells with Ag-nano and carbon wiring deposited using enzyme-coated porous carbon. The maximum power of the biofuel cell with the modified AgNW electrodes was $0.29 \mu \mathrm{W}$ at $180 \mathrm{mV}$, and the corresponding power density was $0.98 \mu \mathrm{W} / \mathrm{cm}^{2}$. The maximum power of the biofuel cell with the carbon wiring was $0.04 \mathrm{pW}$ at $50 \mathrm{mV}$, and the corresponding power density was $0.12 \mu \mathrm{W} / \mathrm{cm}^{2}$. The superior performance of the biofuel cell with AgNWs was considered to be due to its high electrical conductivity.

The maximum power density of $0.98 \mu \mathrm{W} / \mathrm{cm}^{2}$ was comparable to that of previously reported glucose biofuel cells [4-15].

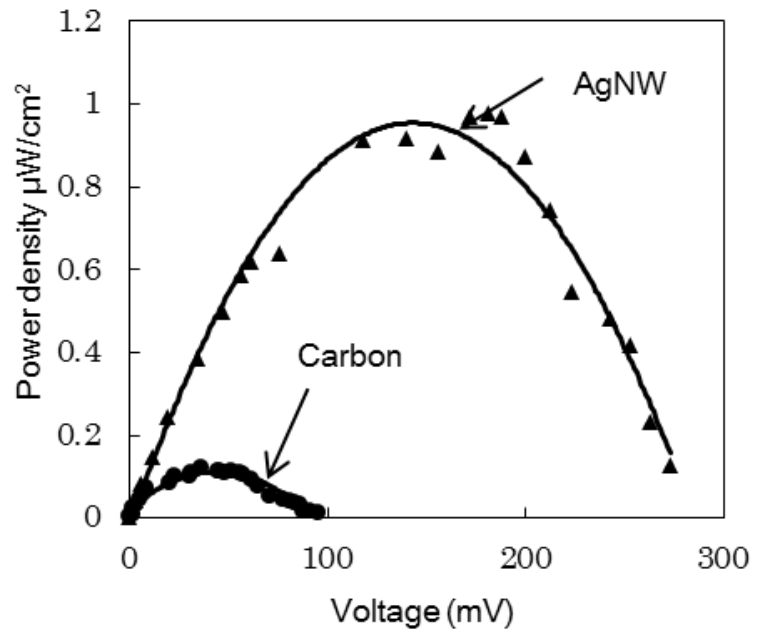

Fig. 9. The relationships between the power density and the voltage for the biofuel cells with Ag-nano and carbon wiring deposited using enzyme coated porous carbon.

\section{Conclusion}

In this study, we fabricated a flexible, stretchable glucose-biofuel cell with Ag nano wires on a PDMS substrate. The biofuel cell investigated consists of a porous carbon anode (area of $30 \mathrm{~mm}^{2}$ ) modified by glucose oxidase and ferrocene, and a cathode (area of $30 \mathrm{~mm}^{2}$ ) modified by bilirubin oxidase. The anode and the cathode were 
connected with $\mathrm{Ag}$ nanowiring. The maximum power of $0.29 \mu \mathrm{W}$ at $180 \mathrm{mV}$ (corresponding with power density of $0.98 \mu \mathrm{W} / \mathrm{cm}^{2}$ ) was realized by immersing the biofuel cell in a PBS with a glucose concentration of $100 \mathrm{mM}$, at room temperature.

\section{References}

1. A. Zebda, L. Renaud, M. Cretin, C. Innocent, R. Ferrigno and S. Tingry, Sens. Actuators, $B$ Chem., 149 (2010) 44.

2. L. Brunel, J. Denele, K. Servat, K. B. Kokoh, C. Jolivalt, C. Innocent, M. Cretin, M. Rolland and S. Tingry, Electrochem. commun., 9 (2007) 331.

3. Y. Zou, C. Xiang, L. Yang, L. X. Sun, F. Xu, and Z. Cao, Int. J. Hydrogen Energy, 33 (2008) 4856.

4. M. Togo, A. Takamura, T. Asai, H. Kaji and M. Nishizawa, J. Power Sources, 178 (2008) 53.

5. X. Wei and J. Liu, Front. Energy Power Eng. China, 2 (2008) 1.

6. Y. Kamitaka, S. Tsujimura, N. Setoyama, T. Kajino and K. Kano, Phys. Chem. Chem. Phys., 9 (2007) 1793.

7. N. Mano, F. Mao, W. Shin, and A. Heller, Chem. Commun., 2 (2003) 518.

8. E. Katz, A. F. Bückmann and I. Willner, $J$. Am. Chem. Soc., 123 (2001) 10752.

9. N. Mano, F. Mao and A. Heller, J. Am. Chem. Soc., 125 (2003) 6588.

10. P. Cinquin, C. Gondran, F. Giroud, S. Mazabrard, A. Pellissier, F. Boucher, J. P. Alcaraz, K. Gorgy, F. Lenouvel, S. Mathé, P. Porcu and S. Cosnier, PLoS One, 5 (2010) 1.

11. A. Zebda, S. Cosnier, J. P. Alcaraz, M. Holzinger, A. Le Goff, C. Gondran, F. Boucher, F. Giroud, K. Gorgy, H. Lamraoui and P. Cinquin, Sci. Rep., 3 (2013) 1516.

12. A. Zebda, C. Gondran, A. Le Goff, M. Holzinger, P. Cinquin and S. Cosnier, Nat. Commun., 2 (2011) 370.

13. Y. Fukushi, S. Koide, R. Ikoma and W. Akatsuka, J. Photopolym. Sci. Technol., 26 (2013) 303.

14. T. Miyake, K. Haneda, S. Yoshino and M.
Nishizawa, Biosens. Bioelectron., 40 (2013) 45.

15. K. Haneda, S. Yoshino, T. Ofuji, T. Miyake and M. Nishizawa, Electrochim. Acta, 82 (2012) 175.

16. Z. Yu, L. Li, Q. Zhang, W. Hu and Q. Pei, Adv. Mater., 23 (2011) 4453.

17. X. Ho, J. N. Tey, W. Liu, C. K. Cheng and J. Wei, J. Appl. Phys., 113 (2013) 044311.

18. T. Akter and W. S. Kim, ACS Appl. Mater. Interfaces, 4 (2012) 1855.

19. L. Song, A. C. Myers, J. J. Adams and Y. Zhu, ACS Appl. Mater. Interfaces, 6 (2014) 4248 .

20. M. S. Lee, K. Lee, S. Y. Kim, H. Lee, J. Park, K. H. Choi, H. K. Kim, D. G. Kim, D. Y. Lee, S. Nam and J. U. Park, Nano Lett., 13 (2013) 2814.

21. F. Xu, J. W. Durham, B. J. Wiley and Y. Zhu, ACS Nano, 5 (2011) 1556.

22. M. Amjadi, A. Pichitpajongkit, S. Lee, S. Ryu and I. Park, ACS Nano, 8 (2014) 5154.

23. H. Y. Mi, Z. Li, L. S. Turng, Y. Sun and S. Gong, Mater. Des., 56 (2014) 398.

24. M. Park, J. Im, M. Shin, Y. Min, J. J. Park, H. Cho, S. Park, M. B. Shim, S. Jeon, D. Y. Chung, J. Bae, U. Jeong and K. Kim, Nat. Nanotechnol., 7 (2012) 803.

25. P. Lee, J. Lee, H. Lee, J. Yeo, S. Hong, K. H. Nam, D. Lee, S. S. Lee and S. H. Ko, $A d v$. Mater., 24 (2012) 3326.

26. H. Hocheng, C. M. Chen, Y. C. Chou and C. H. Lin, Microsyst Technol, 16 (2010) 423.

27. C. P. Siu and M. Chiao, J. Microelectromech S, 17 (2008) 1329.

28. H. Kudo, T. Sawada, E. Kazawa, H. Yoshida, Y. Iwasaki and K. Mitsubayashi, Biosens. and Bioele., 22 (2006) 558.

29. C. Y. Chen, C. L. Chang, T. F. Chien and C. H. Luo, Sens. and Actuators A: Physical, 203 (2013) 20.

30. F. Xu and Y. Zhu, Adv. Mater., 24 (2012) 5117.

31. S. P. Lacour, D. Chan, S. Wagner, T. Li and Z. Suo, Appl. Phys. Lett., 88 (2006) 204103. 